\title{
De Kairós a Kronos: metamorfoses do trabalho na linha do tempo
}

\author{
José Clerton de Oliveira Martins ${ }^{\mathrm{I}, 1}$, Cássio Adriano Braz de Aquino ${ }^{\mathrm{II}, 2}$, \\ Iratan Bezerra de Sabóia ${ }^{\mathrm{II}, 3}$ e Adriana de Alencar Gomes Pinheiro ${ }^{\mathrm{I}, 4}$ \\ ${ }^{\mathrm{I}}$ Universidade de Fortaleza (Fortaleza, CE) \\ ${ }^{\text {II }}$ Universidade Federal do Ceará (Fortaleza, CE)
}

\begin{abstract}
Neste estudo, buscamos refletir sobre as transformações percebidas na apreensão do termo "trabalho" frente à relação entre sujeito e tempo. Elegemos como ponto de partida de tais ponderações dois mitos gregos, Kronos e Kairós, para demarcar a percepção daquela sociedade em seu estágio mítico-erótico, no intuito de delimitar o registro de um significado do que gera vida (Kairós) e outro do que a consome (Kronos). Sem pretensões de estabelecer definições arraigadas, a proposta é sugerir diálogos e reflexões para delinearmos algumas elaborações sobre o trabalho ao longo da linha do tempo de nossa sociedade ocidental, sem perder a noção de que se trata de mais um recorte possível, entre tantos. O estudo é resultado de investigação bibliográfica, portanto de abordagem qualitativa a partir de consulta a livros, artigos e outras pesquisas publicadas em bases de dados sobre a temática. Os resultados nos levam a inferir que nas sociedades mítico-eróticas os processos de trabalho centravam-se em atividades indistintas, e estas se confundiam com a existência das comunidades, não havendo clara distinção entre trabalho e ócio. Por outro lado, a mudança nos meios de produção e os processos de industrialização conduziram os sujeitos à alienação na cadeia produtiva e ao conhecimento apenas parcial desse processo. Com a vinculação dessa lógica à produção em série, o sujeito não mais vendia produtos, mas, sim, seu tempo. A partir disso, inferimos que, apesar das evoluções registradas, o trabalho segue em sua perspectiva contemporânea, ora no tempo de Kairós, quando se permite a expressão subjetiva, ora tomado por Kronos, quando o sujeito é destituído de sua possibilidade criativa.
\end{abstract}

Palavras-chave: Trabalho, Tempo de trabalho, Tempos sociais, Transformações laborais.

From Kairos to Kronos: metamorphosis of work in history

In this study we aim at considering the changes perceived in the comprehension of the term "work" in relation to subject and time. As a starting point of our consideration, we chose Kronos and Kairos, two Greek myths, to establish a perception of that society in its mythic-erotic state, since we intend to mark the meaning of something that generates life (Kairos) and that of what consumes it (Kronos). Without intending to establish final definitions, our proposal are some dialogues and considerations aiming at delineating a few formulations on the subject work, following the history of Western society, without ignoring the fact that it is only one possible viewpoint among many. This study results from a bibliographical research and, as such, it has a qualitative approach to books, essays and other researches published in relevant databases concerning the theme. The results lead us to infer that in mythic-erotic societies the processes of work were centered in unclear activities, which were mingled with the existence of communities, and there was no clear distinction between work and leisure. On the other hand, changes in production means and industrialization processes led workers to alienation in the production chain and to a limited conscience of this process. Linking this logic to serial production, the worker was no more selling products, but his own time. Thus, we could infer that, notwithstanding some developments, working follows its contemporary perspective, sometimes in Kairos time, when it allows a subjective expression, sometimes taken by Kronos, when the worker is destitute of his creative capabilities.

Keywords: Work, Work time, Social time, Work changes.

1 Professor titular do Programa de Pós-graduação em Psicologia, Universidade de Fortaleza. Coordenador do OTIUM Laboratório de Estudos sobre Ócio, Trabalho e Tempo Livre.

2 Professor do Programa de Pós-Graduação em Psicologia, Universidade Federal do Ceará. Coordenador do NUTRA - Núcleo de Psicologia do Trabalho.

3 Mestre em Psicologia pela Universidade Federal do Ceará. Coordenador do ERGA - Núcleo de Estudos do Trabalho. Pesquisador Associado do Laboratório Interdisciplinar de Pesquisa e Intervenção Social da PUC-Rio - LIPIS. Professor do Curso de Psicologia da Universidade Federal do Ceará - Sobral.

4 Doutoranda e Mestre em Psicologia pela Universidade de Fortaleza. Professora dos cursos de Administração de Empresas e de Direito da Faculdade Paraíso de Juazeiro do Norte, Ceará. Membro do OTIUM - Laboratório de Estudos sobre Ócio, Trabalho e Tempo Livre. 


\section{Introdução}

$\mathrm{R}_{\mathrm{c}}^{\mathrm{c}}$ efletir sobre a passagem do trabalho entre um tempo apropriado subjetivamente e o tempo controlado/cronometrado que emergiu após a Revolução Industrial, bem como as implicações nas mudanças das relações entre o homem e seu trabalho, em virtude dessa passagem, é o cerne deste trabalho.

$\mathrm{Na}$ tentativa de desenvolvermos a proposta, partimos da percepção sobre o que se infere sobre o trabalho nas culturas pré-industriais, acentuando pontos da relação entre trabalho e tempo. Logo, refletimos sobre a mudança de paradigma que se estabeleceu a partir da produção industrializada e as novas relações de trabalho que dali emergiram, enfatizando as novas formas de apropriação do tempo no trabalho, assim como o controle desse tempo.

Apresentamos algumas reflexões tomando como base os pontos levantados durante o estudo, de acordo com os autores que serviram de referencial. Atentos quanto às dicotomias e aproximações reveladas, optamos como possibilidade conclusiva por uma perspectiva complexa.

\section{O tempo de trabalho entre Kronos e Kairós}

$\mathrm{Na}$ diversidade da mitologia grega, encontramos duas possibilidades de compreensão do tempo que podem ser convocadas para as representações do tempo de trabalho. Essa apropriação é válida pela possibilidade de aproximação que se apresenta contemporaneamente: o tempo de Kronos (em grego, крóvos, isto é, a duração controlada) e o tempo de Kairós (em grego, kaıрós, o momento certo ou oportuno).

Ao cunharem duas palavras para qualificarem o tempo vivido, cada uma das possibilidades (Kronos/Kairós) designava não apenas uma qualidade de tempo, mas também indicava uma representação divina vinculada à possibilidade.

Kronos pertencia à raça dos Titãs (a segunda geração de governança da criação) e era retratado como um ser que devorava os filhos tão logo estes nasciam. Esse comportamento retrata a característica de um tempo destruidor, até mesmo de suas próprias criações. Mitologicamente, justificava-se pela profecia de que ele próprio seguiria a sina do pai: um de seus filhos iria matá-lo e assumir seu lugar como senhor da criação. Assim, temeroso dessa sina, buscava eliminar o perigo. É da palavra grega kronos que derivam cronômetro, cronológico, cronograma etc.; todas revelam o aspecto de um tempo que é controlado e que se finda.

Por outro lado, Kairós simboliza um tempo que, ao contrário de Kronos, é irredutível e transcorre de uma forma relativa à presentificação de cada um que o percebe e o vivencia (Ribeiro, 1962). Na realidade, é a representação do tempo subjetivo, que pode ser a eternização do momento pela presentificação em sua elaboração. Significa também o momento oportuno, a oportunidade agarrada. Era representado por um jovem atlético, com asas nos pés, que tinha como principal característica transitar em velocidade vertiginosa por todo o mundo de forma aleatória, sendo, assim, impossível se prever um encontro com ele (Ribeiro, 1962).

Dessa forma, há duas categorias de tempo: uma lógica, contabilizável, quantificável, comum e previsível, que pode ser mensurada e dividida em anos, meses, dias, horas minutos e segundos, um tempo universal e que serve de norteador para vários processos sociais. A segunda categoria é um tempo não racional, qualificável, pessoal, imprevisível e mutável, que não pode ser compartilhado com o outro, que, mesmo sendo enunciado, só pode ser entendido plenamente por aquele que o vive. 
Kronos representa esse tempo que todos conhecemos, contado em 24 horas para um dia. O passado sucedido pelo presente, que será ultrapassado pelo futuro. Já Kairós é aquela sensação de que, durante uma atividade prazerosa, o tempo corre rápido; e um espaço de tempo muito menor sob uma tarefa desgastante parece não ter fim se ao mesmo tempo se eterniza na recordação do vivido.

\section{Tempo e trabalho em Kairós - possibilidades nas sociedades pré- industriais}

O homem das sociedades mítico-eróticas, ou das chamadas sociedades pré-industriais, não possuía uma definição para trabalho. Donkin (2003) aponta estudos realizados em tribos que viviam em uma sociedade de coleta e caça cujos membros não diferenciam o que comumente se considera trabalho de outras atividades diárias e rotineiras.

Isso se dava porque todas as atividades exercidas "nas sociedades pré-históricas... só cobriam as necessidades básicas e dela participavam todos os membros do grupo" (Marín, 1993, p. 613). Franco Júnior e Chacon (1986) observam que, até o fim do Paleolítico (700.000 a 10.000 a.C.), o homem vivia realmente de forma nômade, um predador como outros animais, mas, já no período Mesolítico (10.000-7.000 a.C.), aprendeu a domesticar os animais e, mesmo sobrevivendo da caça e coleta, houve um início de sedentarismo.

A Revolução Neolítica, que aconteceu no fim daquele período (7.000-3.000 a.C.), modificou drasticamente a relação do homem com a natureza, pois foi ali que este passou a domesticar animais de forma mais ampla e a cultivar a terra. Rezende Filho (1997) aponta que "foi a atividade agrícola, principalmente, que permitiu que o homem passasse a viver em comunidades estáveis, sedentarizando-o, e introduzindo a noção de trabalho coletivo". O trabalho coletivo ainda não conhecia uma distinção de categoria, porque não existia a noção de posse particular. Apenas os pertences pessoais, como roupas e pequenos adereços, eram propriedade particular; todo o resto era coletivo (Franco Júnior \& Chacon, 1986).

Ao contrário do que se faz hoje, não existiam tempos dedicados a certas ações. Por exemplo, o ato de educar era concomitante ao ato de preparar a comida. Alimentava-se ao mesmo tempo que se educava; brincava-se enquanto se caçava ou se cuidava dos recémnascidos. Essa configuração das atividades cotidianas fazia que toda ação representasse todo o processo de existir em compartilhamento, em que todos participavam de tudo e, por isso, eram sujeitos atores de seus tempos, convocando cisões apenas quando das necessárias ritualidades das festas.

Foi sobre esse cenário de sedentarização que o homem conheceu a possibilidade de um aumento tal na produção de bens de subsistência, que permitiu um grande crescimento populacional e, consequentemente, um sistema cada vez mais avançado de trocas. É a partir desse ponto que se desenvolveram sociedades à margem dos rios (principais pontos de terra fértil), as chamadas civilizações hidráulicas.

Nesse período, encontramos o primeiro traço claro de divisão do trabalho ${ }^{5}$ o homem já estabelecido em uma porção de terra (propriedade privada ${ }^{6}$ ) passa a criar diferenciações, e dali divide o trabalho a ser desenvolvido entre diferentes partes da sociedade (as castas ou classes). Nessas sociedades, o homem era livre para trabalhar da maneira que melhor lhe conviesse,

\footnotetext{
5 Alguns autores, como Donkin (2003), defendem que a primeira divisão do trabalho social foi feita no momento em que se separaram homens e mulheres para determinadas tarefas, ainda no período primitivo.

6 Trata-se aqui "propriedade privada" no sentido de estar concentrada, mas a propriedade, assim como outros diversos meios de produção, eram de domínio do Estado.
} 
entretanto ele devia uma parcela de sua produção e ofertava pequenos trabalhos compulsórios para manter o Estado.

No Período Arcaico (século VIII a.C.), com a queda da atividade agropastoril e das propriedades comunais, observa-se grande utilização de escravos. A propriedade privada, o desenvolvimento dos mercados e da produção e a escassez de suprimentos (o que forçava uma demanda maior de trabalho) deram condições para o surgimento da escravidão em uma proporção nunca antes vista (Donkin, 2003), em detrimento do modelo adotado nas civilizações hidráulicas, pois, segundo Rezende Filho (1997):

As civilizações hidráulicas, que haviam submetido suas populações a formas de trabalho compulsório, fizeram-no nominalmente em razão de uma necessidade coletiva, transformando-o em parte integrante de um rito religioso. E o que foi mais importante, este trabalho compulsório era temporariamente limitado e regular, o que fez com que os homens que o prestavam continuassem a ser, sob todos os aspectos, livres, quer fossem camponeses, quer fossem artesãos (p. 24).

É importante frisar que se mantinha a estrutura geral entre tempo e trabalho: o homem trabalhava segundo sua própria determinação; o trabalho compulsório assinalado pelo autor não estava vinculado a uma jornada como conhecemos hoje. A prestação de serviço era feita por pagamento de parte da produção ou por um serviço. O que está em jogo aqui é a tarefa, e não o tempo total que ela consome, e assim a relação tempo e trabalho mantém-se autocondicionada, ou seja, o trabalhador determina seu próprio tempo de produção.

A utilização em larga escala da escravidão modifica drasticamente o conceito de trabalho que vigorava. Primeiramente, o homem é dissociado dos frutos de seu trabalho e passa a ser mero instrumento de produção; outra característica modificada foi o tempo de trabalho. Nesse contexto, para o homem livre, o tempo de trabalho era autogerido; para um escravo, todo seu tempo é ocupado com trabalho. O trabalho manual, antes executado por camponeses, passa a ser dissociado da liberdade e torna-se sinônimo de escravidão. Ao escravo é permitido apenas o descanso, e mesmo este é diretamente ligado ao trabalho, pois serve como repositor de energia, para ser novamente exaurido na atividade laboral.

Pode-se inferir que esse pensamento talvez seja a origem da associação entre trabalho manual e repetitivo a uma condição degradante do homem, que em tempos futuros se transformará na classificação do trabalho como atividade negativa - pensamento que só será revertido com a ideologia protestante.

Com a diminuição das guerras (principal fonte de captação de mão de obra escrava), o sistema escravista ruiu por volta do século II AD e foi dando lugar, de forma gradativa, a um sistema que tinha como principal ponto de atuação a intervenção dos governantes, mas deixando inalterada a relação entre trabalho manual e liberdade (Rezende Filho, 1997). Isso se dava principalmente nos trabalhos com a terra: o homem que a cultivava era teoricamente livre (por não ser escravo), entretanto estava preso à terra que trabalhava, não podendo abandonála.

Os trabalho de manufatura passaram a ser executados em larga escala por artesãos, e estes, juntamente com os comerciantes, deveriam estar afiliados a corporações e prestar serviços voluntários ao Estado. Esse novo tipo de organização econômica foi chamado de dirigismo estatal e vigorou entre os séculos III e V AD (Franco Jr. \& Chacon, 1986).

No fim do século $\mathrm{V}$ d.C., o dirigismo estatal vai dando lugar gradativamente a um modo de produção, na Alta Idade Média, que ficou conhecido como sistema dominial, definido por Franco Jr. e Chacon (1986) da seguinte forma:

As transformações sofridas pelo sistema agrícola do Baixo Império Romano e as novas condições sociais e políticas vindas da difusão do cristianismo e da penetração germânica deram origem 
aos domínios, isto é, grandes propriedades agrárias trabalhadas basicamente por mão de obra dependente (p. 47).

A propriedade era privada e, mesmo que existisse uma pequena quantidade de terra trabalhada por seus proprietários com o auxílio de suas famílias e alguns poucos escravos, predominava o sistema de domínios, que se caracterizava, segundo Franco Jr. e Chacon (1986) e Rezende Filho (1997), não por seu tamanho, mas por estar dividido em duas partes: as terras do senhor e a parte cedida ao camponês, que não era escravo - mas estava preso à terra que cultivava - e trabalhava segundo seu próprio tempo, devendo ao senhor das terras uma parcela da produção e a prestação de trabalhos voluntários (que era a maior contribuição).

Com o declínio do Estado Carolíngio (séculos VIII e IX), surgiu o sistema senhorial, que teve como expressão política o feudalismo. Neste sistema, os senhores de terra passaram a se apropriar do resultado da produção camponesa com taxas cada vez maiores, e os artesãos fecharam-se cada vez mais em suas corporações de ofícios, o que obrigava os camponeses a buscar meios alternativos de renda - entre eles, o trabalho assalariado e a fabricação caseira de artesanato. $\mathrm{O}$ trabalho assalariado ganhou força, mas a gestão de contrato entre empregador e empregado era feita individualmente, não existindo regra sobre tempo e serviço ou remuneração.

No feudalismo, existiam os contratos estabelecidos, mas não havia uma lei que unificasse a contratação de mão de obra. Cada contrato era feito de forma individualizada, no sentido de que em um mesmo estabelecimento existiam pessoas com a mesma função, mas com tempo de trabalho diferente, ou com salários que não eram uniformes.

Historicamente, o que se define como saída da Idade Média (sistemas dominial e senhorial e, consequentemente, feudalismo; os dois primeiros são classificados como sistema econômico funcional) e ingresso na Idade Moderna foi resultado principalmente de três fatores: (a) a crescente onda comercial que fez declinar o sistema dominial e modificou a base do sistema econômico, obrigando-o a voltar-se para o mercado de comércio em função da crescente monetarização forçada por um ingresso de mão de obra livre e assalariada; (b) a contínua expansão do próprio sistema funcional; (c) crises - agrária, monetária e demográfica que aconteceram no período. Assim nasce o sistema comercial, em que as relações de trabalho sofreram uma intervenção nunca antes vista, que marcou profundamente as relações de trabalho. Franco Jr. e Chacon (1986) a definem assim:

O setor em que o Estado mais fez sentir sua presença foi o dos preços e salários. A primeira legislação a respeito foi a Ordinance of labourers (1349), pela qual se determinava a obrigatoriedade de trabalho para homens e mulheres com menos de 60 anos e pelos mesmos salários anteriores à peste negra. Procurava-se, assim, enfrentar a penúria de mão de obra e a tendência altista dos salários, que estavam arruinando sobretudo os pequenos e médios proprietários rurais. A ordenação estabelecia, ainda, medidas punitivas para quem a desrespeitasse. Tal legislação foi completada pouco depois, pelo Statute of labourers (1351), mais minucioso e mais rigoroso... (p. 90).

Essas foram, de forma efetiva, as primeiras intervenções regulamentadas que a relação entre tempo e trabalho (e os salários) sofreram. O precedente aberto pelo Ordinance of labourers e pelo Statute of labourers acabou gerando novas intervenções e maiores controles, que, apoiados na lógica das guildas de artesões e outros agrupamentos de trabalhadores de um mesmo ramo, culminaram nos modelos sindicais e nas leis trabalhistas que regem categorias de trabalhadores nos dias de hoje.

Até esse momento histórico, percebia-se uma predominância de tempo autocondicionado para o trabalho e uma vinculação das atividades laborais aos ciclos naturais: estações, dias e noites etc. Assim, além de determinar a duração de sua atividade, ou pelo menos ter alguma gerência sobre ela, o trabalho tinha uma lógica cíclica e comum: as durações de trabalho e descanso eram socialmente compartilhadas, sugeridas pela ordem natural. A 
partir das transformações em consequência de uma economia que se desenvolvia, o trabalho passa a adquirir novas formas, orientado pela exigência do controle da força que o fazia brotar. Iniciam-se novos domínios sobre o tempo de trabalho. Começa o reinado de Kronos.

\section{Tempo e trabalho em Kronos - possibilidades nas sociedades pós- revolução industrial ocidental}

A crescente monetarização da economia e o alargamento dos mercados consumidores tornaram-se os alicerces de onde surgiria o capitalismo. Embalado por uma demanda que não parecia decair, o mercado adotou severas mudanças na produção e nas relações de trabalho.

É importante destacar que tudo é um processo, só podendo ser compreendido dentro de uma perspectiva histórica. O primeiro fator é um aumento gradativo no trabalho assalariado, que eleva também a quantidade de moeda circulando no mercado - em detrimento das trocas diretas de mercadoria -, aliado à expansão do mercado em virtude do consumo e da circulação de moeda (isso facilita o crescimento de uma economia baseada na comercialização de produtos) e à necessidade de novas formas de produção mais ágeis e eficientes, gerando uma demanda por segmentação do trabalho.

Essa prática não é uma criação do período. Na verdade, séculos antes, o homem já dividia o trabalho a ser realizado dentro de um grupo, e mesmo na Idade Média existia uma segmentação do trabalho - entretanto, essa divisão não tinha caráter rígido, e seus componentes compartilhavam um mesmo espaço, conhecendo a técnica de produção de todo o produto, mas atuando em apenas uma parte, para tornar sua consecução mais rápida.

Outro fator determinante foi a evolução do pensamento de associação do trabalho manual e os dogmas na Igreja. Já no século XIII, iniciou-se uma aproximação entre esses dois polos pelo aparecimento de ordens monásticas e militares que uniam fé e ação (Rezende Filho, 1997). No século XVI, um movimento iniciado por Martinho Lutero e João Calvino fechou definitivamente essa aproximação: a Reforma Protestante levantava-se prioritariamente contra a indulgência do clero católico e sua vida de regalias, que contrastava com o esforço diário dos fiéis. É então que nasce a ética protestante, conjunto de interpretações pelas quais Lutero e Calvino fazem uma vinculação indissolúvel entre o trabalho e a salvação divina (Weber, 2003).

É apenas neste ponto que o trabalho passa a ser positivado, pois séculos antes, com o advento do cristianismo, o trabalho era dotado de caráter negativo. Isso é refletido na crença de que o homem passou a trabalhar e a ganhar seu sustento com o suor do rosto após a expulsão do Éden. Trata-se de herança da crença grega que via no trabalho manual um ato de desumanização; o trabalho que aproximava os homens dos deuses era o criativo, intelectual e político. E esse pensamento já remetia a uma associação a trabalho manual e escravidão.

Esse fundamento passa a ser revertido quando o pensamento protestante começa a ganhar corpo na Europa, principalmente a partir das traduções do evangelho, que pode ser lido por uma população que não tinha, até então, acesso ao seu conteúdo - a não ser por meio das homilias dos padres durante as missas ou de outra forma por intermédio da Igreja. As Escrituras Sagradas tornam-se domínio público, e as ideias de Lutero e Calvino foram cada vez mais discutidas. Mesmo sob pesada repressão, os protestantes se proliferam e, com eles, a ideia de que acumular riqueza não é um pecado: o trabalho não só engrandece o homem, mas é um meio de salvação, e o importante é como os frutos (riqueza) desse trabalho são utilizados.

No século XVIII, esse pensamento - aliado à crescente necessidade de produção - e grandes avanços tecnológicos favoreceram na Inglaterra, já amplamente impregnada pelo pensamento protestante, um cenário propício para o aparecimento do lugar fabril. Inicia-se 
uma grande convenção sobre o trabalho; acontece, então, uma homogeneização das relações entre empregador e empregado.

Marx (1978) aponta que a mola propulsora do capitalismo está na capacidade daqueles que detêm os meios de produção de gerarem riqueza a partir da exploração de mão de obra e da supervalorização do produto. É justamente em nome de uma maior produtividade e de um maior barateamento do produto que os grandes empregadores daquela época criam jornadas de trabalho longas e segmentam o tempo e a linha de produção.

É preciso evidenciar três fases distintas da Revolução Industrial. Ao contrário de diversos teóricos que apontam duas grandes fases desse processo, acreditamos que existem outros parâmetros para entendê-lo e a mudança que gerou no mundo do trabalho. A primeira foi o surgimento das máquinas a vapor, o que possibilitou um avanço no poder de produção. A segunda foi a implantação do relógio nas fábricas; é por esta lógica que o tempo de produção passa a ser controlado em nome de um ganho de produtividade, seguindo a introdução de uma lógica da rapidez da máquina a vapor e do controle do tempo de produção. Daí, as jornadas são uniformizadas e pode-se pensar em linhas de produção e heterocondicionamento do tempo laboral.

Por fim, a luz elétrica chega às fábricas, e, com isso, a rotina fabril e de trabalho é drasticamente modificada: se antes obedecia a um ciclo natural de dia e noite, como trabalho e descanso, agora fazia-se dia no interior das fábricas, e as jornadas podiam ser estendidas, criando uma noção não mais cíclica do tempo de trabalho, mas retilínea e progressiva. A máquina seguia em ritmo constante, e restava ao homem adaptar-se e também produzir neste ritmo.

Jornadas eram seguidas por jornadas de novas levas de trabalhadores, criando o que hoje se conhece como produção contínua ou 24 horas, culminando nas cidades que funcionam dia e noite. Se existem trabalhadores em todos os turnos, os serviços e comércio precisam, também, funcionar na mesma lógica, de modo a atendê-los.

Marx (1978) aponta que o tempo de trabalho passa a ter uma prevalência sobre o próprio trabalho no capitalismo industrial; . Isso quer dizer que a mão de obra já não vende sua força de trabalho propriamente dita, mas o seu tempo de trabalho, pois, excluído dos meios de produção e sem dominar a técnica de feitura do produto como um todo, resta ao trabalhador empregar sua força de trabalho vendendo seu tempo; e, para tanto, este é dividido e controlado a fim de maximizar a produção. O próprio tempo, assim, passa a ser, segundo o autor, uma moeda de troca; o artesão recebia o pagamento por peça ou trabalho concluído, o trabalhador fabril recebe por uma jornada de trabalho.

Essa prevalência do tempo de trabalho como moeda e da busca por uma produtividade cada vez maior apoiou-se na lógica protestante, demonstrada por Weber (2003). Hassard (1996) explicita esse foco no trabalho e uma dedicação cada vez maior da seguinte maneira:

A análise do processo do trabalho oferece-nos uma imagem reificada do tempo: o tempo é primeiramente aquele da produção; os outros tempos devem encontrar seu lugar de algum modo nas margens do processo de produção (p. 181).

Poderíamos, nesse ponto, alinhar o trabalho de tempo autogerido (o trabalho em Kairós) como um trabalho libertador e enobrecedor da condição humana; e, ao contrário, aquele trabalho temporalmente controlado e rigidamente determinado retira do sujeito a característica que mais lhe promove enobrecimento.

Esse é um pensamento corriqueiro quando deparamos com o assunto. Entretanto. Marx (1978) faz uma outra diferenciação do trabalho: para ele, pode ser dividido em trabalho concreto e em trabalho abstrato. O primeiro não está relacionado com a concretude direta do produto ou do resultado final, mas com a obtenção de um produto com valor de uso - este se 
dá pela utilidade e pela necessidade social (coletiva) do fruto daquele trabalho, sendo este uma fonte de identificação entre aquele que produz e aquilo que é produzido. $\mathrm{O}$ trabalho abstrato é desvinculado de uma identificação direta do sujeito que trabalha com o produto que dele provém; é o trabalho alienado e que gera um produto com valor de troca, ou seja, um valor de mercado, mais que de utilidade. Sobre a produção de valor e a produção de trabalho, Marx (1978, p. 228) arremata:

Se compararmos o processo de produzir valor com o processo de trabalho, verificamos que este consiste no trabalho útil que produz valores de uso. A atividade neste processo é considerada qualitativamente, em suma espécie particular, segundo seu objetivo e conteúdo. Mas, quando se cogita da produção de valor, o mesmo processo de trabalho é considerado apenas sob o aspecto quantitativo.

Para ele, o esvaziamento do trabalho como atividade que forma o sujeito está vinculado à falta de sentido dada ao trabalho. E essa falta de sentido, o autor alinha ao momento em que o trabalhador está tão imerso e alienado em uma infinita cadeia produtiva, que já não consegue se reconhecer no produto final de seu trabalho. Falta-lhe o próprio tempo da reflexão.

A centralidade do mundo do trabalho na sociedade contemporânea fez surgir a inevitável temporalidade laboral como a temporalidade principal no contexto social. A vinculação é lógica, pois, uma vez que o trabalho assume posição social privilegiada, sua temporalidade também exerce um poder cada vez mais coercitivo (Elias, 2001). É neste contexto que podemos pensar no trabalho, e na sua temporalidade intrínseca, como categoria privilegiada para refletirmos sobre o sofrimento psíquico a que o sujeito contemporâneo está submetido.

Assim, o tempo sagrado, vivido pelas sociedades antigas (Dejours, 1996), como o tempo central nestas vai dando lugar paulatinamente ao tempo do trabalho. Com a Revolução Industrial, essa vinculação temporal fica ainda mais presente, e o tempo laboral passa a ser inflacionado e a submeter de forma cada vez maior os outros tempos sociais.

\section{Considerações finais}

Podemos, com base na discussão levantada, inferir sobre os direcionamentos que a sociedade atual aponta para os significados do trabalho entre Kronos e Kairós.

Assim, destaca-se nesse contexto um enraizamento da lógica protestante no mundo ocidental, onde países com predominância católica, como o Brasil, manifestam em sua cotidianidade o pensamento do trabalho como algo enobrecedor, verificando-se o valor do acúmulo de riqueza como algo naturalizado.

Computadores, celulares, aviões, carros, todo esse arsenal tecnológico, liberam o sujeito contemporâneo de atribuições simples e otimizam o tempo. No entanto, à revelia do tempo liberado, o valor arraigado de ser produtivo revela um sujeito orientado pela lógica da produção e do consumo. O tempo de Kairós é cada vez mais distante na possibilidade corrente do mundo ocidental superconsumista e apressado, reflexos da lógica do capital.

Se, no início do protestantismo, esse movimento se dava em função de ganho espiritual e moral, hoje essa amarração parece ser meramente estética, fazendo incidir um pensamento de consumo em detrimento do de trabalho.

O próprio trabalho passou a ser um meio para o acúmulo de material a ser comprado, consumido. A atividade que antes era um fim em si mesma - o trabalho - passou a ser um veículo pelo qual se vem ascendendo a um estatuto de consumidor. A primazia do ter em 
detrimento do ser e o caráter de veículo para obtenção de meio de consumo vem transformando o trabalho, de uma categoria antes assumida como subjetivação da condição do sujeito, em um lugar de esvaziamento de sentido.

O grande impacto dessa realidade na relação entre tempo e trabalho foi o progressivo afastamento de jornadas homogêneas para uma crescente demanda de relativização do tempo de trabalho. O tempo do trabalho não mais é o do relógio de ponto; é o da tarefa a ser cumprida, do almoço de negócios. Na realidade, o trabalho nos acompanha via aparelhos de última tecnologia que nos convocam em qualquer espaço e tempo. E, se estamos tratando de uma sociedade que tem como centralidade a atividade laboral, essas implicações são vastas.

Os demais tempos sociais, que antes conviviam lado a lado com o tempo de trabalho, foram diminuindo gradativamente: o tempo da família, o de lazer... enfim, o tempo autogerido do sujeito começou a ser tomado por esse tempo de trabalho, que invadiu, inclusive, as horas de descanso.

Hoje, esse tempo autogerido busca locais à margem do plano central, ocupado pelo tempo laboral, que se estende bem além do trabalho formalmente constituído: planejamentos de reuniões feitos em casa, decisões de trabalho tomadas nos intervalos para o almoço, jantares de negócios, cursos de línguas, MBAs, cursos de informática são alguns exemplos de ocupação de tempo fora do ambiente do trabalho, devido à necessidade de aprimoramento que o mercado exige.

Em contrapartida, hoje se percebe um movimento que anuncia uma reflexão sobre a necessidade de se ter um tempo autogerido, ou seja, um tempo na perspectiva kairológica. Sobre isso, percebemos, por exemplo, grandes empresas que mantêm funcionários em suas folhas de pagamento sem a obrigatoriedade do comparecimento ao local de trabalho e que podem realizar suas tarefas desde casa, de acordo com seu próprio tempo. Verifica-se o aumento do número de profissionais liberais, que trabalham segundo uma lógica de serviço, e não de tempo de serviço, mesmo tendo a possibilidade de ingresso no mercado formal. Ocorre o retorno, ainda tímido, do pensamento do ócio, sobre um tempo de ser do sujeito, em que se retoma o tempo autogerido perdido nas longas jornadas de trabalho. Vê-se a crescente preocupação com a qualidade de vida dentro e fora do trabalho; e recentes movimentos revelam esta tendência, como o movimento Slow, que prega a desaceleração da vida principalmente do trabalho.

O tempo autogerido aponta, assim, para um lugar da necessidade do sujeito. Se a história nos mostra uma evolução em que esse tempo foi se perdendo dentro do contexto social e econômico, este mesmo contexto revela uma certa busca de âmbitos para o desenvolvimento de um tempo mais autônomo, seja na forma de novos modelos de trabalho e vinculação institucional (profissionais liberais e profissionais que trabalham por projetos, e não por horas de trabalho), seja sob o símbolo de um mercado de consumo do próprio tempo e a retomada de um fazer autogerido.

\section{Referências}

Aquino, C. A. B. A. (2003a). Temporalidade como elemento chave no estudo das transformações no trabalho. Athenea Digital, 4, 151-159.

Aquino, C. A. B. A. (2003b). Tiempo y Trabajo: un análisis de la temporalidad laboral en el sector de ocio - hostelería y turismo - y sus efectos en la composición de los cuadros temporales de los trabajadores. Tese de Doutorado, Universidad Complutense de Madrid, Madrid.

Dejours, C. (1996). Uma nova visão do sofrimento humano nas organizações. In J. F. Chanlat (Coord.), O indivíduo na organização: dimensões esquecidas (4⿳亠丷厂 ed.). São Paulo: Atlas.

Donkin, R. (2003). Sangue, suor E̊ lágrimas: a evolução do trabalho. São Paulo: M. Books do Brasil. 
Durkheim, E. (1978). As formas elementares da vida religiosa. São Paulo: Abril Cultural.

Elias, N. (2001). Do tempo. São Paulo: Rocco.

Franco Jr., H. \& Chacon, P. P. (1986). História da economia geral. São Paulo: Atlas.

Hassard, J. (1996). Tempo de trabalho: outra dimensão esquecida nas organizações. In J. F. Chanlat (Coord.), O indivíduo na organização: dimensões esquecidas (3르 ed.) (pp. 175-193). São Paulo: Atlas.

Marín, M. R. (1993). Trabajo. In A. A. Baztán (Ed.), Diccionário temático de antropología. Barcelona: Boixareu Universitaria.

Martins, J. C. O. (2001). La cultura ritual festiva en el marco laboral del nordeste brasileiro: el caso de los conductores de autobuses de Fortaleza. Tese de Doutorado, Faculdade de Psicología, Universidade de Barcelona, Barcelona.

Marx, K. (1978). O capital. São Paulo: Ciências Humanas.

Munnè, F. (1990). Psicosociologia del tiempo libre: um enfoque critico. Cidade do México: Trillas.

Pinheiro, A. A. G. (2003). Sofrimento psíquico nas relações de trabalho: caso representativo no setor gráfico cearense. Dissertação de Mestrado, Universidade de Fortaleza, Fortaleza.

Pronovost, G. (1996). Sociologie du temps. Bruxelas: De Boek Université.

Rezende Filho, C. B. (1997). História econômica geral (3ํㅜ ed.). São Paulo: Contexto.

Ribeiro, J. C. (1962). Vocabulário e fabulário da mitologia. São Paulo: Martins.

Salis, V. D. (2004). Ócio criador, trabalho e saúde: lições da antiguidade para a conquista de uma vida mais plena em nossos dias. São Paulo: Claridade.

Sue, R. (1995). Temps et ordre social. Paris: PUF.

Traverso-Yépez, M. A. (2002). Trabalho e saúde: subjetividades em um contexto de precariedade. In A. M. Mendes, L. O. Borges \& M. C. Ferreira (Orgs.), Trabalho em transição, saúde em risco (pp. 111-132). Brasília: Universidade de Brasília.

Weber, M. (2003). A ética protestante e o espírito do capitalismo (2 ${ }^{\underline{a}}$ ed.). São Paulo: Pioneira.

\section{Endereço para correspondência}

clerton@unifor.br, brazaquino@ufc.br, iratan@gmail.com, adriana_alencar@oi.com.br 